\title{
Fluvial Fluxes of Water, Suspended Particulate Matter, and Nutrients and Potential Impacts on Tropical Coastal Water Biogeochemistry: Oahu, Hawai'i
}

\author{
D. J. Hoover · F. T. Mackenzie
}

Received: 16 September 2007/Accepted: 11 June 2009/Published online: 28 July 2009

(C) The Author(s) 2009. This article is published with open access at Springerlink.com

\begin{abstract}
Baseflow and storm runoff fluxes of water, suspended particulate matter (SPM), and nutrients ( $\mathrm{N}$ and $\mathrm{P}$ ) were assessed in conservation, urban, and agricultural streams discharging to coastal waters around the tropical island of Oahu, Hawai 'i. Despite unusually low storm frequency and intensity during the study, storms accounted for 8-77\% (median 30\%) of discharge, 57-99\% (median 93\%) of SPM fluxes, 11-79\% (median 36\%) of dissolved nutrient fluxes and 52-99\% (median $85 \%$ ) of particulate nutrient fluxes to coastal waters. Fluvial nutrient concentrations varied with hydrologic conditions and land use; land use also affected water and particulate fluxes at some sites. Reactive dissolved $\mathrm{N}: \mathrm{P}$ ratios typically were $\geq 16$ (the 'Redfield ratio' for marine phytoplankton), indicating that inputs could support new production by coastal phytoplankton, but uptake of dissolved nutrients is probably inefficient due to rapid dilution and export of fluvial dissolved inputs. Particulate $\mathrm{N}$ and $\mathrm{P}$ fluxes were similar to or larger than dissolved fluxes at all sites (median $49 \%$ of total nitrogen, range $22-82 \%$; median $69 \%$ of total phosphorus, range $49-93 \%$ ). Impacts of particulate nutrients on coastal ecosystems will depend on how efficiently SPM is retained in nearshore areas, and on the timing and degree of transformation to reactive dissolved forms. Nevertheless, the magnitude of particulate nutrient fluxes suggests that they represent a significant nutrient source for many coastal ecosystems over relatively long time scales (weeks-years), and that reductions in particulate nutrient loading actually may have negative impacts on some coastal ecosystems.
\end{abstract}

Keywords Tropical coastal ecosystems - Tropical streams · Fluvial fluxes · Storm runoff · Land use · Water quality · Nutrients

\footnotetext{
D. J. Hoover ( $₫)$

Department of Ecology and Evolutionary Biology, University of California Long Marine Laboratory, Santa Cruz, CA 95060, USA

e-mail: dan.hoover@gmail.com

Present Address:

D. J. Hoover

U.S. Geological Survey, 400 Natural Bridges Drive, Santa Cruz, CA 95060, USA

F. T. Mackenzie

Department of Oceanography, University of Hawai'i at Manoa, Honolulu, HI 96822, USA
} 


\section{Introduction}

Much research has been devoted to characterizing discharges of water, suspended particulate matter (SPM), and dissolved nutrients from large rivers, which dominate the global flux of water to the ocean (e.g., Meybeck 1982). Milliman and Syvitski (1992) observed that small mountainous rivers, including those on high-standing oceanic islands were underrepresented in global SPM budgets but likely were important, as they often were associated with unusually high sediment yields. The inclusion of these sources does not change estimates of global SPM discharge dramatically (e.g., Syvistski et al. 2005), but SPM discharges from smaller rivers and streams are important regionally, particularly around oceanic islands. Discharges from small mountainous watersheds are more episodic than those from large rivers with a large fraction of annual water and SPM discharges occurring during short-lived storm events (Hoover 2002; Ringuet and Mackenzie 2005; DeCarlo et al. 2007). Small mountainous watersheds and flashy runoff are common on oceanic islands, particularly in the tropics, but little is known about the impacts of runoff on associated coastal ecosystems, which frequently have substantial ecological and economic value. Characterizing fluvial fluxes is critical to understand both the natural functioning of these coastal ecosystems and the potential for human impacts. In addition, while oceanic islands are responsible for only a small fraction of SPM delivery to the global ocean, SPM inputs from these sources may be disproportionately important for regional phosphorus (P) budgets, as $\mathrm{P}$ inputs to the ocean are associated primarily with fluvial SPM (Sundby et al. 1992; Mackenzie 2003).

This article presents hydrologic and water quality data from six streams on the island of Oahu, Hawai 'i. Water, SPM, and nutrient fluxes were calculated to determine the relative contributions of low-flow and storm runoff discharges to annual fluxes, and to assess the effects of land use (agriculture and urbanization) on water quality and nutrient fluxes. Both land use and hydrologic conditions affect the timing and form of nutrient fluxes to coastal waters. The impacts of these fluxes on coastal ecosystems will depend on hydrologic and land use factors, and on the reactivity and retention of individual constituents in coastal waters. However, the impacts of dissolved and particulate nutrients are likely to be quite different with dissolved nutrients probably less important, and particulate nutrients more important, than has been assumed.

\section{Materials and Methods}

\subsection{Study Site}

The island of Oahu is located in the Hawaiian archipelago in the central North Pacific Ocean. Rainfall and stream development are concentrated along the windward (northeast) side of the Koolau mountains (Fig. 1), where steep topography and prevailing northeast tradewinds promote orographic precipitation (Schroeder 1993). Topographic effects also contribute to variability in rainfall, which typically is intermittent but often intense (Cheng and Lau 1973; Schroeder 1993).

The windward side of the Koolau range consists of a series of amphitheater-shaped valleys with steep headwalls and alluvial deposits on valley floors. Streams on the leeward side are deeply incised into an alluvial plateau, and have more moderate gradients than windward streams. Soils on Oahu are diverse, but the wet tropical climate favors rapid weathering and the formation of clays containing iron and aluminum 


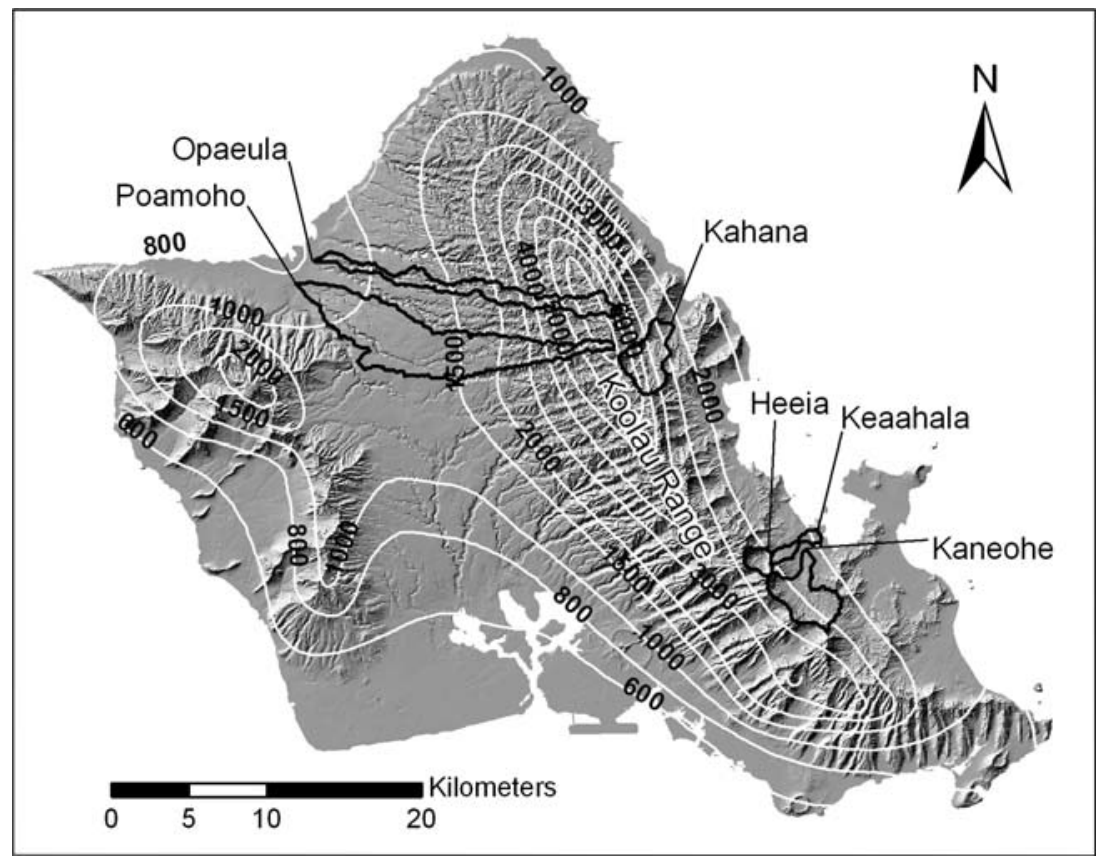

Fig. 1 Study watersheds on the island of Oahu, Hawai'i. Rainfall isohyets (white contours) are in mm

oxyhydroxides (Gavenda et al. 1998) that have a strong affinity for sorbing phosphate (Fox and Searle 1978). Development on Oahu is highly regionalized with extensive urbanization in the city of Honolulu and neighboring areas, and large-scale agricultural development primarily in the central plateau. Agriculture has been dominated for more than 100 years by plantation cultivation of pineapple and sugar cane, although the sugar cane industry ended in 1996. Hawai'i historically has been one of the top users of fertilizer in the United States on a per-acre basis (Tennessee Valley Authority, various years), resulting in considerable inputs of 'new' $\mathrm{N}$ and $\mathrm{P}$ to agricultural watersheds. Areas of Oahu not suitable for agricultural or other development generally have been maintained as conservation land.

Six sites were selected for hydrographic and water quality monitoring (Figs. 1, 2, Table 1). The Kahana and Heeia watersheds contain predominantly conservation land and were used as controls for comparison to watersheds with significant agricultural (Opaeula and Poamoho) and urban (Kaneohe and Keaahala) land use. Artificial and natural hydraulic controls at the Kahana, Kaneohe, Opaeula, and Heeia sites provided stable stream level-todischarge relationships suitable for quantitative determination of discharge and associated SPM and nutrient fluxes. Stream level-to-discharge relationships at these sites were quantified by U.S. Geological Survey (USGS) personnel in conjunction with historical and ongoing USGS streamflow monitoring. Hydraulic controls were poor and no level-todischarge data were available at the Poamoho and Keaahala sites. These sites were monitored primarily for water quality, but relative flow conditions (baseflow vs. storm runoff) were recorded. 


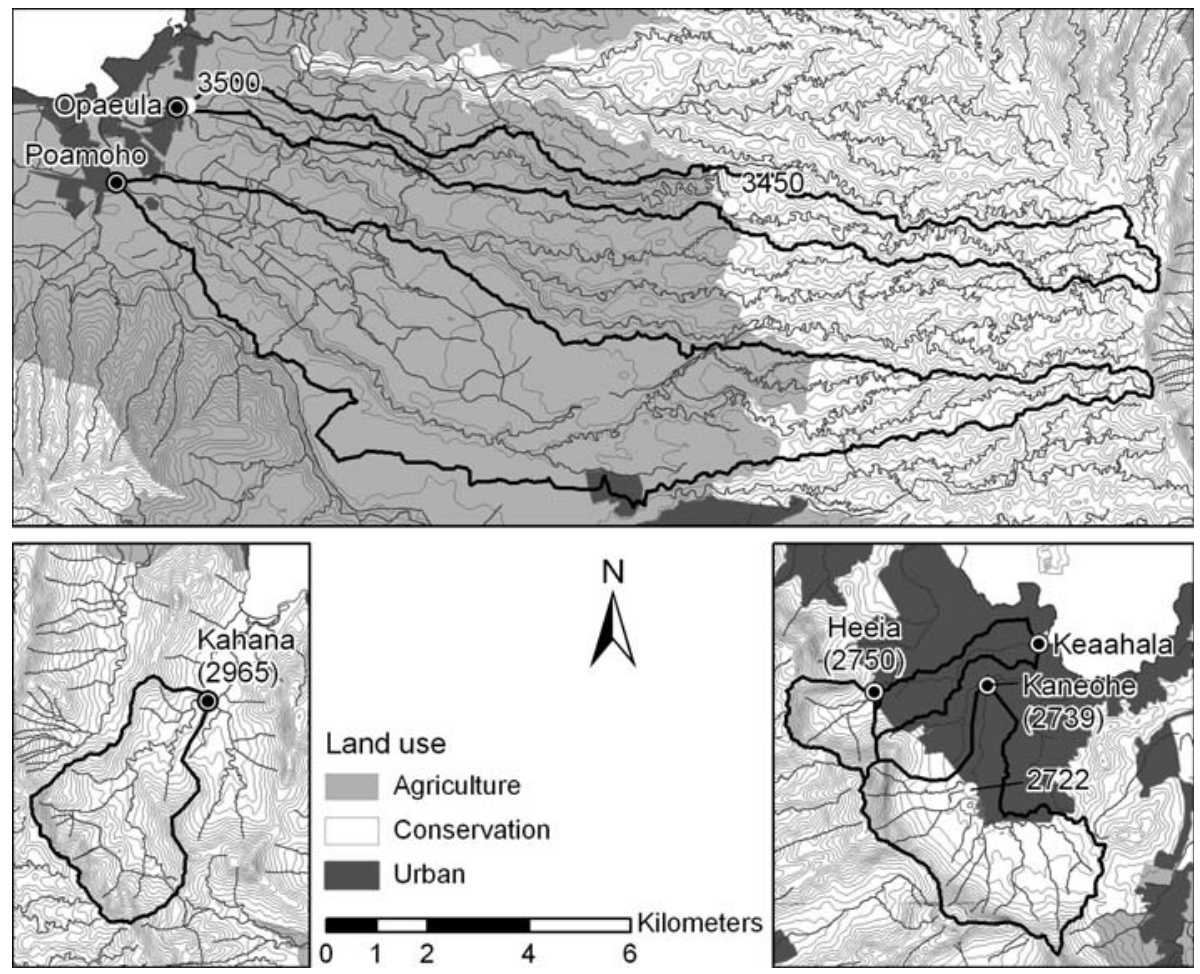

Fig. 2 Land use, topography, and sampling sites in study watersheds. Topographic contours are at 100' intervals. USGS sites are labeled with 4-digit numbers

Table 1 Characteristics of study watersheds

\begin{tabular}{lclllllll}
\hline Watershed & Monitored & \multicolumn{2}{l}{ Elevation (m) } & Area $\left(\mathrm{km}^{2}\right)$ & Rain $^{\mathrm{a}}\left(\mathrm{cm} \mathrm{y}^{-1}\right)$ & $\mathrm{Cons}^{\mathrm{b}}(\%)$ & $\mathrm{Ag}^{\mathrm{b}}(\%)$ & $\mathrm{Urb}^{\mathrm{b}}(\%)$ \\
\cline { 3 - 8 } & \multicolumn{2}{c}{ Station } & Max & & & \\
\hline Kahana (C) & $10 / 97-6 / 00$ & 9 & 750 & 9.69 & 458 & 100 & 0.0 & 0.0 \\
Heeia (C) & $3 / 99-7 / 01$ & 82 & 820 & 2.51 & 235 & 100 & 0.0 & 0.0 \\
Opaeula (A) & $1 / 97-6 / 00$ & 1 & 810 & 15.5 & 323 & 56 & 44 & 0.2 \\
Poamoho (A) & $12 / 97-5 / 99^{\mathrm{c}}$ & 2 & 760 & 45.8 & 176 & 17 & 82 & 1.0 \\
Kaneohe (U) & $1 / 99-7 / 01$ & 12 & 820 & 11.3 & 204 & 84 & 0.0 & 16 \\
Keaahala (U) & $2 / 97-7 / 01$ & 1 & 370 & 2.91 & 171 & 6 & 0.0 & 94
\end{tabular}

Control watersheds are entirely conservation (C) land. Agricultural (A) and urban (U) watersheds include conservation land in upper portions of the watersheds

${ }^{a}$ Rainfall is estimated from median annual rainfall isohyets (http://www.hawaii.gov/dbedt/gis/rainfall.htm)

b Land use data are from zoning maps (http://www.hawaii.gov/dbedt/gis/slud91.htm); small areas of noncompliant land use are present in some areas

c Gap from 7/98-1/99 


\subsection{Field Methods}

Streams were instrumented with Isco model 3230 and 4230 recording flowmeters and 24-sample model 2900 and 3700 automatic water samplers or model 6700 samplers with model 730 recording flow modules. Because stream levels in Hawai' $i$ change rapidly during storm runoff events (Wu 1969), stream levels were recorded at 5 min intervals. Sampling was initiated automatically when stream levels exceeded a preset threshold; thresholds and sampling intervals were adjusted at each site to obtain samples from as wide a range of storm runoff conditions as possible, including the initial rise, peak, and recession portions of storm hydrographs. At most sites, stream levels returned to the sampling threshold within one to a few hours, and a 15 or 30 min sampling interval provided an appropriate range of samples. At the Poamoho Stream site, a one hour interval ultimately was used due to the much slower recession of storm runoff levels at this site. Flowmeters and samplers were serviced as soon as possible after storm events or biweekly during low-flow conditions. Baseflow samples were collected manually at the time of sampler servicing. All samples were collected in acid-cleaned bottles and kept on ice until processing in the laboratory.

\subsection{Laboratory Methods}

Samples were analyzed for dissolved inorganic nitrogen [nitrate plus nitrite = $\mathrm{NO}_{3}{ }^{-}+\mathrm{NO}_{2}{ }^{-}$(hereafter referred to as $\mathrm{NO}_{3}{ }^{-}$or nitrate due to the negligible quantity of $\mathrm{NO}_{2}{ }^{-}$normally present), ammonium $=\mathrm{NH}_{4}{ }^{+}$(hereafter referred to as ammonia)] and total dissolved nitrogen (TDN), dissolved inorganic phosphorus [measured as soluble reactive phosphorus (SRP), but often assumed equivalent to $\mathrm{PO}_{4}{ }^{3-}$ (phosphate)] and total dissolved phosphorus (TDP), and dissolved silica ( $\mathrm{Si}$ ), as well as for suspended particulate matter (SPM) and associated organic carbon (POC), organic nitrogen (PON), total phosphorus (TPP), and inorganic phosphorus (PIP). Dissolved organic nitrogen (DON) and phosphorus (DOP) and particulate organic phosphorus (POP) were calculated by difference from total and inorganic constituents.

Some constituents, particularly the dissolved inorganic nutrients (nitrate, ammonia, and phosphate) participate in reactions that can alter concentrations following sample collection. Preservatives could not be used with automatic samplers, but Kotlash and Chessman (1998) showed that autosampling and sample storage had only minimal effects on inorganic nutrient concentrations. In addition, another study (Dugan 1977) that used an automated sampler with near-daily sample retrieval at a site very close to our Kaneohe site obtained results very similar to ours, indicating that storage effects on our dissolved nutrient concentrations were minimal.

For dissolved constituents, samples were filtered through acid-cleaned, deionized water (DI) rinsed Whatman GF/C filters (nominal pore size $1.2 \mu \mathrm{m}$ ), and the filtrate was frozen for later analysis. The use of GF/C filters may result in systematic differences in dissolved/ particulate nutrient partitioning compared to methods using other filters (e.g., GF/F filters with a nominal pore size of $0.7 \mu \mathrm{m}$ ), but differences observed in tests generally were very small (Hoover, unpublished data) and do not affect the overall conclusions of this study. Similarly, use of uncombusted filters may result in some increase in apparent dissolved organic concentrations, but the amount of potential contamination is also small compared to the concentrations found in stream waters (Hoover, unpublished data) and can be ignored. Filtration through glass fiber filters and freezing can also affect dissolved silica results (American Public Health Association et al. 1995), but was not a significant factor in this study due to the high silica concentrations in samples and the small freezing effect 
(average $2 \%$ reduction, Hoover unpublished data). For total organic $\mathrm{N}$ and $\mathrm{P}$ determinations, an aliquot of thawed sample was UV oxidized to convert dissolved organic compounds to inorganic forms (Armstrong and Tibbits 1968). Oxidized samples then were analyzed for inorganic $\mathrm{N}$ and $\mathrm{P}$ species using standard colorimetric methods (American Public Health Association et al. 1995) on Technicon AAII autoanalyzers. UV oxidation sometimes is less efficient at converting combined $\mathrm{P}$ to inorganic $\mathrm{P}$ than methods that use chemical oxidation (Ridal and Moore 1990; Monaghan and Ruttenberg 1999), so total and dissolved organic P results from this study should be considered minimum estimates.

SPM was determined by filtering an aliquot of well-mixed sample onto a preweighed, combusted $2.5 \mathrm{~cm}$ Whatman GF/C filter and drying overnight at $60^{\circ} \mathrm{C}$. Filters were cooled to room temperature in a desiccator, reweighed, and SPM calculated from the incremental weight and the volume of sample filtered. SPM filters then were analyzed for POC and PON on a Carlo Erba NC2500 Elemental Analyzer. TPP and PIP were determined using a modified version of Aspila et al. (1976). SPM was collected on uncombusted GF/C filters from two sample aliquots and dried. One filter was extracted in $1 \mathrm{~N} \mathrm{HCl}$ to convert particulate inorganic P (PIP) to dissolved phosphate, and the second was combusted for $2 \mathrm{~h}$ at $500^{\circ} \mathrm{C}$, followed by extraction in $6 \mathrm{~N} \mathrm{HCl}$ to convert TPP to dissolved phosphate. Extracts were neutralized and analyzed for dissolved phosphate, and PIP and TPP were calculated from the mass of phosphorus extracted and the original sample weight. While the combustion temperature used was slightly lower than in the Aspila method $\left(500^{\circ} \mathrm{C}\right.$ vs. $\left.550^{\circ} \mathrm{C}\right)$, the acid used was stronger $(6 \mathrm{~N}$ vs. $1 \mathrm{~N})$, and tests indicated that the method generally extracted as much or slightly more TPP than the Aspila method (S. Vink, unpublished data).

\subsection{Hydrographic Data Processing, Flux, and Yield Calculations}

Stream level data were converted to discharge at the four sites with quantitative level-toflow relationships using a 15-minute interval subset of the level record and Isco Flowlink $3^{\mathrm{TM}}$ software. Gaps in stream level data were spliced using data from adjacent (Kahana and Heeia) or nearby (Kaneohe) USGS monitoring sites. At the Opaeula site, a regression of daily discharge from upstream USGS site 3450 (USGS site numbers are reported here as 4-digit abbreviations of the full number: $16 \times x \times x 00$ ) and daily discharge at the study site was used to estimate missing daily discharges. At the Poamoho and Keaahala sites, stream levels were converted to 'analogue' flows using exponential level-to-flow relationships estimated from relationships observed at other study sites (Hoover 2002). Analog flows are useful for visualizing stream dynamics and for assessing flow dependence in nutrient concentrations, but provide information only on relative flow conditions (i.e., lower- vs. higher-flow) and thus were not used for flux calculations.

For flux calculations, 15 min flow increments were separated into baseflow and storm runoff categories based on flow frequency and chemical criteria. In 1997, a relatively normal runoff year, the lower $90 \%$ of flow increments was classified as baseflow and the remainder as storm runoff (cf., Hill 1996). However, baseflow conditions prevailed more than $90 \%$ of the time in the lower runoff years due to the relative lack of storm events, so changes in dissolved silica and nutrient concentrations instead were used to locate the shift from baseflow to storm runoff in those years (see Nutrients). Water fluxes then were computed by summing flow increments. Incremental (15 min) SPM fluxes were estimated from 15 min flows using analytical functions derived for each site (see Results) and summed to generate daily and longer term fluxes. At the Opaeula site, SPM fluxes for periods with only daily flow data were estimated from a daily SPM yield versus daily discharge relationship derived from available 15 min data. Nutrient fluxes then were calculated by 
multiplying water or SPM fluxes by associated dissolved or particulate nutrient concentrations. Characteristic baseflow and storm runoff nutrient concentrations were determined at each site by defining a flow break based on changes in silica and nutrient concentrations and calculating median concentrations for samples below and above the break (see Results). Water, SPM, and nutrient yields were calculated at each site by dividing fluxes by the area of the contributing watershed upslope of the sampling site. In order to facilitate comparisons across sites, runoff, SPM, and nutrient fluxes were also estimated for some years using USGS discharge data and our SPM and nutrient concentration data.

\section{Results}

\subsection{Streamflow}

Storm runoff occurred throughout the year, but was more frequent and intense during the winter months (October-March). Instantaneous discharges ranged across 2 to 4 orders of magnitude at each site, but storm peaks typically lasted only minutes to tens of minutes and flows returned to near-background levels within a few hours (Fig. 3). Storm hydrographs from the leeward Opaeula and Poamoho sites recovered more slowly than hydrographs from windward sites. At the Poamoho and Kaneohe sites, recovery was also affected by human modifications to stream channels that caused stormflows to accumulate at or upstream of the monitoring sites, resulting in a more gradual recession than would have been observed in unmodified channels. Baseflows increased slightly following storms then declined gradually over periods of days to weeks. Baseflows also occasionally dropped and recovered suddenly at some sites, probably due to temporary upstream diversions by watershed residents.

Variations in annual runoff and in storm contributions to discharge can be seen in cumulative runoff curves (Fig. 4), where storm inputs produce step increases in the more gradual increases associated with baseflow discharges. The relative contributions of baseflow and storm runoff varied considerably from year to year and between sites. In 1997, the highest runoff year in the study, storms contributed a larger fraction of total discharge than in any other year, except at the Kahana site, where storm contributions were relatively constant throughout the study. Storms dominated annual discharge at the Opaeula site in all years except 1998, which was one of the lowest runoff years on record, coinciding with the culmination of the 1997-1998 El Niño event. Storms were least important at the Heeia and Kaneohe sites due to the consistently elevated baseflows at those sites.

\subsection{Suspended Particulate Matter}

SPM concentrations increased exponentially with flow at all sites, but exhibited a great deal of variability (Fig. 5). Cumulative SPM yield curves (Fig. 6) show the dominant role of storm events in SPM discharges at all sites with flat or moderately sloped baseflow segments linked by step increases associated with storms. Variable storm contributions caused annual SPM yields to differ dramatically between years with yields dropping 6090\% from 1997 to 1998. SPM yields also varied between sites: in 1997, Kahana and Heeia yields were similar but 2- to 3-fold higher than yields at the Opaeula and Kaneohe sites, while 1998 yields at Kahana and Heeia were quite different, as were yields at Opaeula and Kaneohe. At most sites, baseflow SPM was a very minor contributor to annual yields. The one exception was Kaneohe, where baseflow SPM averaged 33\% of the annual yield due to unusually high SPM concentrations in low-flow samples and relatively low storm yields. 

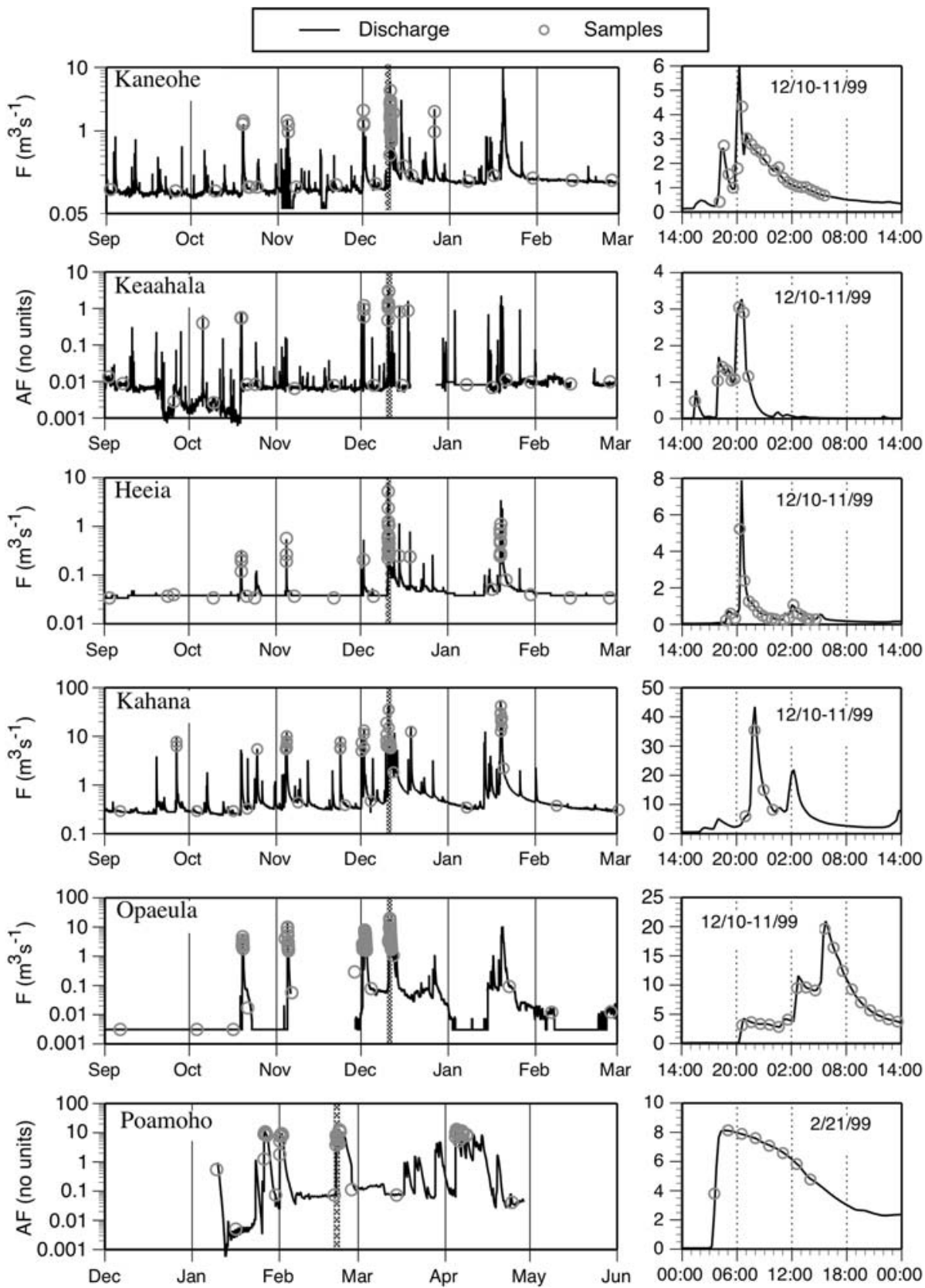

Fig. 3 Representative hydrographs and samples collected at study sites. Left panels show 6 month periods from September 1999 through February 2000, except at the Poamoho site (December 1998 through May 1999). Log scale is used to show full range of flow dynamics. One-day details of 12/10-11/1999 storm event (shaded region in left panels, 2/21/1999 event for Poamoho) are shown in right panels using linear scale. $F$ Discharge, $A F$ Analog discharge) 

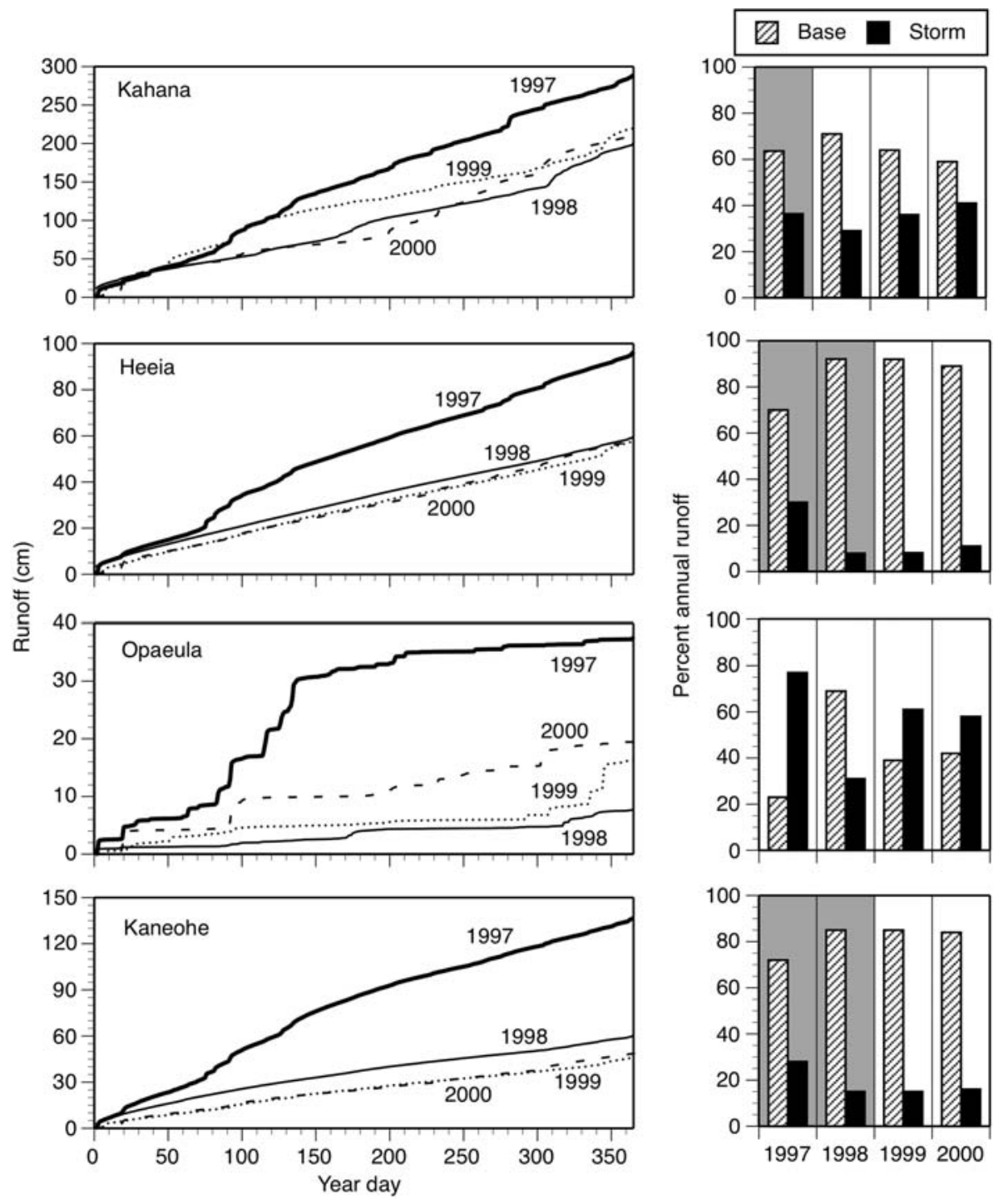

Fig. 4 Cumulative runoff at study sites with quantitative flow data (left panels), and baseflow and storm runoff as percent of total (right panels). Non-study year data (gray backgrounds) are calculated primarily using USGS discharge data

\subsection{Dissolved Nutrients: Nitrogen and Phosphorus}

Concentrations of dissolved species exhibited considerable variability, particularly in intermediate and high-flow samples, but many showed significant flow dependency (Fig. 7). Determination of flow dependency was facilitated by silica analyses. Although dissolved silica is taken up by freshwater diatoms, in fast-flowing streams uptake is negligible compared to the concentration difference between groundwater and surface runoff, so silica is frequently used as a tracer for groundwater in streams (Visher and Mink 1964; 

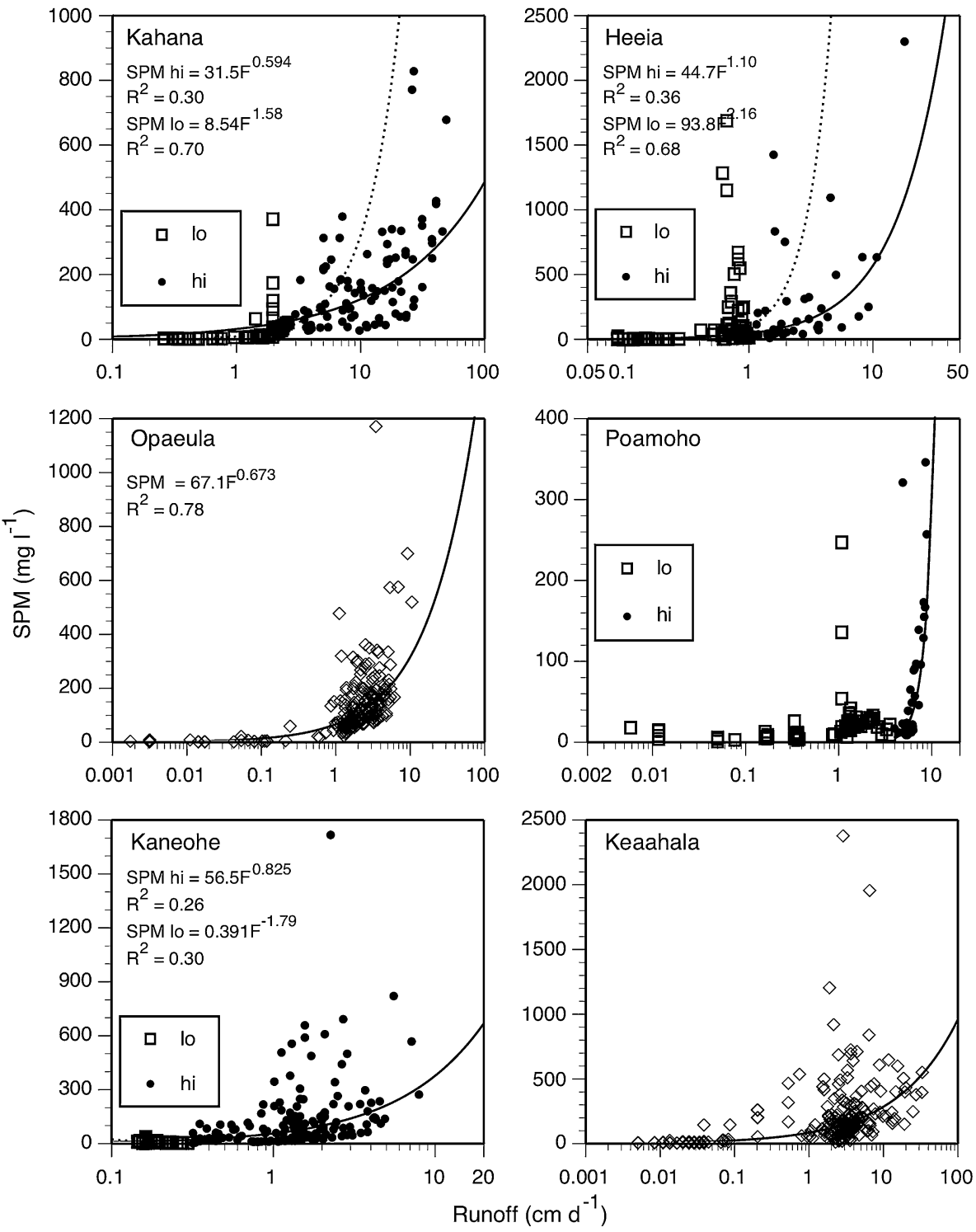

Fig. 5 Suspended particulate matter (SPM) concentrations at study sites. No regression equations are shown for the Poamoho and Keaahala sites because quantitative flow data are not available from those sites. Analog runoffs plotted at these sites are unitless

Tenorio et al. 1969; Hufen et al. 1980). Silica concentrations at all sites declined with flow, and were reasonably well characterized by power functions, consistent with mixing of groundwater-dominated silica-rich baseflow and silica-poor storm runoff.

Flow dependency in nutrient concentrations was observed most frequently for nitrogen species. At the conservation sites, all of the nitrogen species increased in storm runoff samples (Fig. 7). Except for ammonia, similar but larger increases were seen at the urban sites, while trends at the agricultural sites were weak or absent. For phosphorus, trends were 

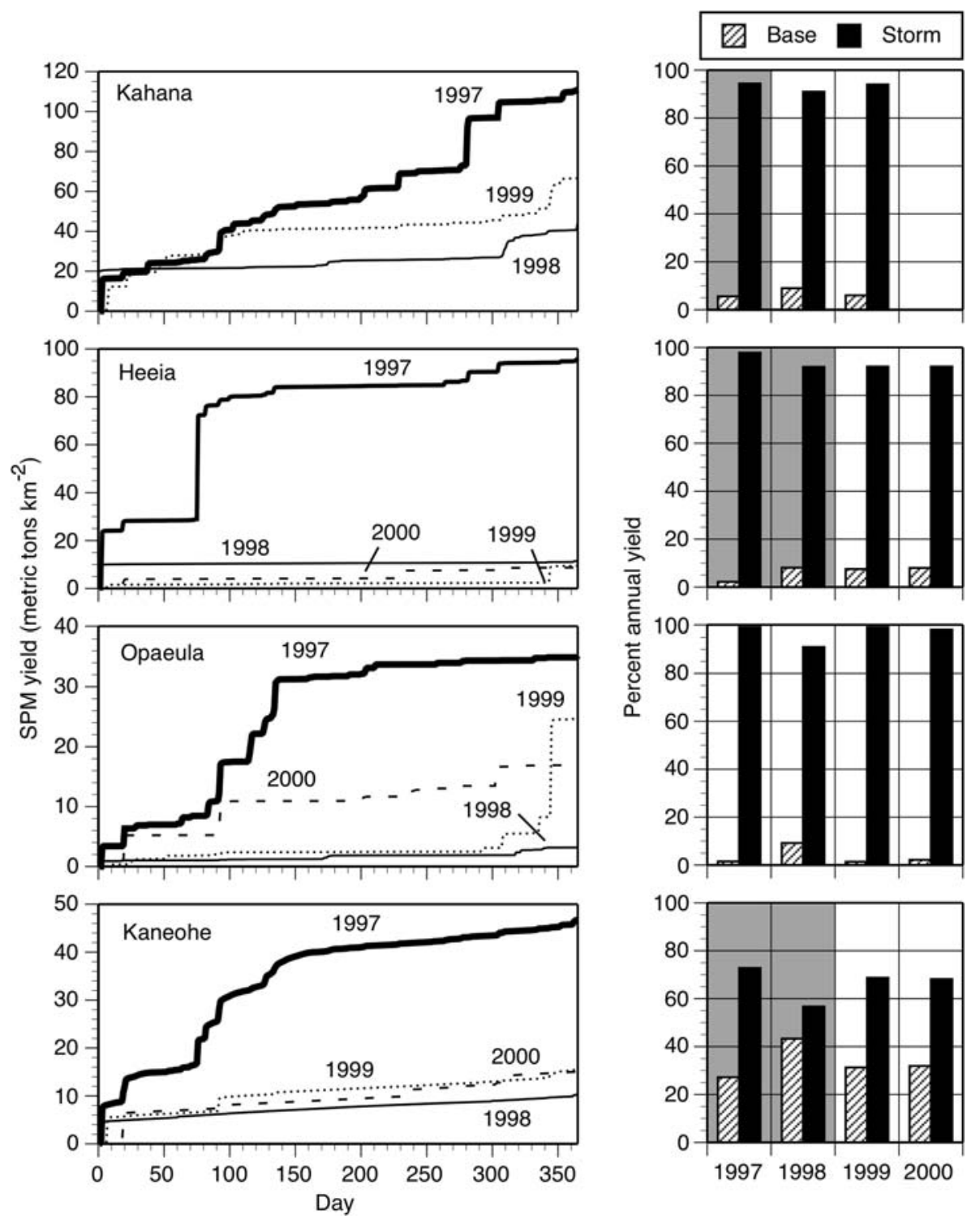

Fig. 6 Cumulative suspended particulate matter (SPM) yields at study sites with quantitative flow data (left panels), and annual yield from baseflow and storm runoff as percent of total (right panels). Data from nonstudy years (gray backgrounds) primarily are estimated using USGS discharge data

weak or absent at the conservation and agricultural sites, but strong positive trends were seen at urban sites. Different $(P \leq 0.05)$ characteristic concentrations for many species were observed when samples were separated into baseflow and storm runoff categories (Fig. 8, Table 2), particularly nitrogen at the conservation and urban sites. Agricultural sites, by contrast, had statistically indistinguishable nitrogen concentrations in baseflow and storm runoff samples. Phosphorus concentrations differed in baseflow and storm runoff at urban sites and at one conservation site (Heeia), but were similar at agricultural sites. 

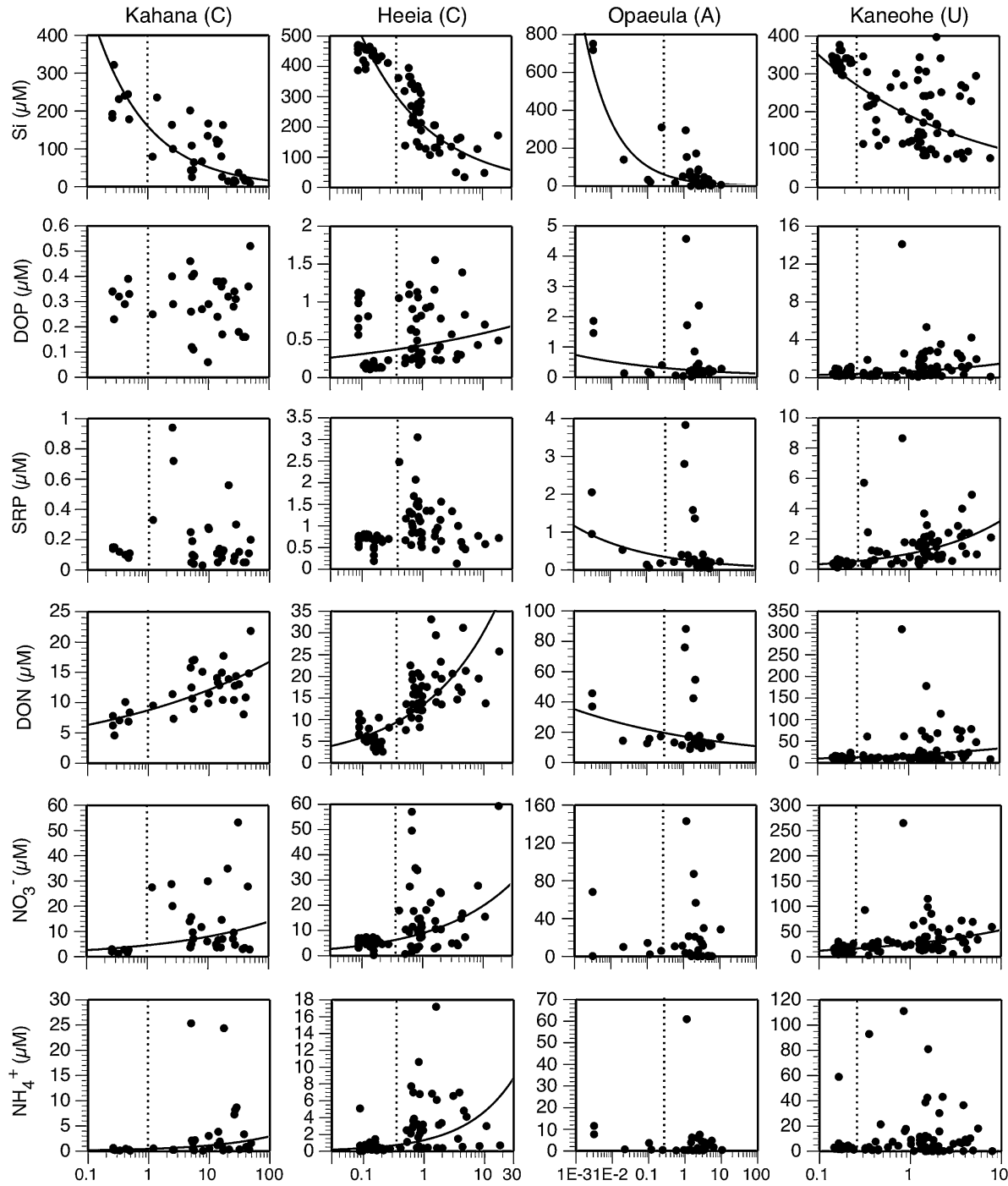

Runoff $\left(\mathrm{cm} \mathrm{d}^{-1}\right)$

Fig. 7 Dissolved nutrient concentrations at sites with quantitative flow data. Regression fits are shown only where the fit explains more than $5 \%$ of the variability in the data. Dashed vertical line is baseflow/storm runoff break (see text). Sites are coded by land use: $C$ conservation, $A$ agriculture, $U$ urban

Concentration differences between sites that had the same land use classification generally were smaller than between sites that had different land use, with the exception of SRP, which was unusually high in both baseflow and storm runoff samples at the Heeia site.

\subsection{Particulate Nutrients: Nitrogen, Phosphorus, and Carbon}

Flow-dependent trends generally are clearer in SPM quality (nutrient content) than in dissolved nutrient concentrations, particularly at high flows where the majority of SPM is 

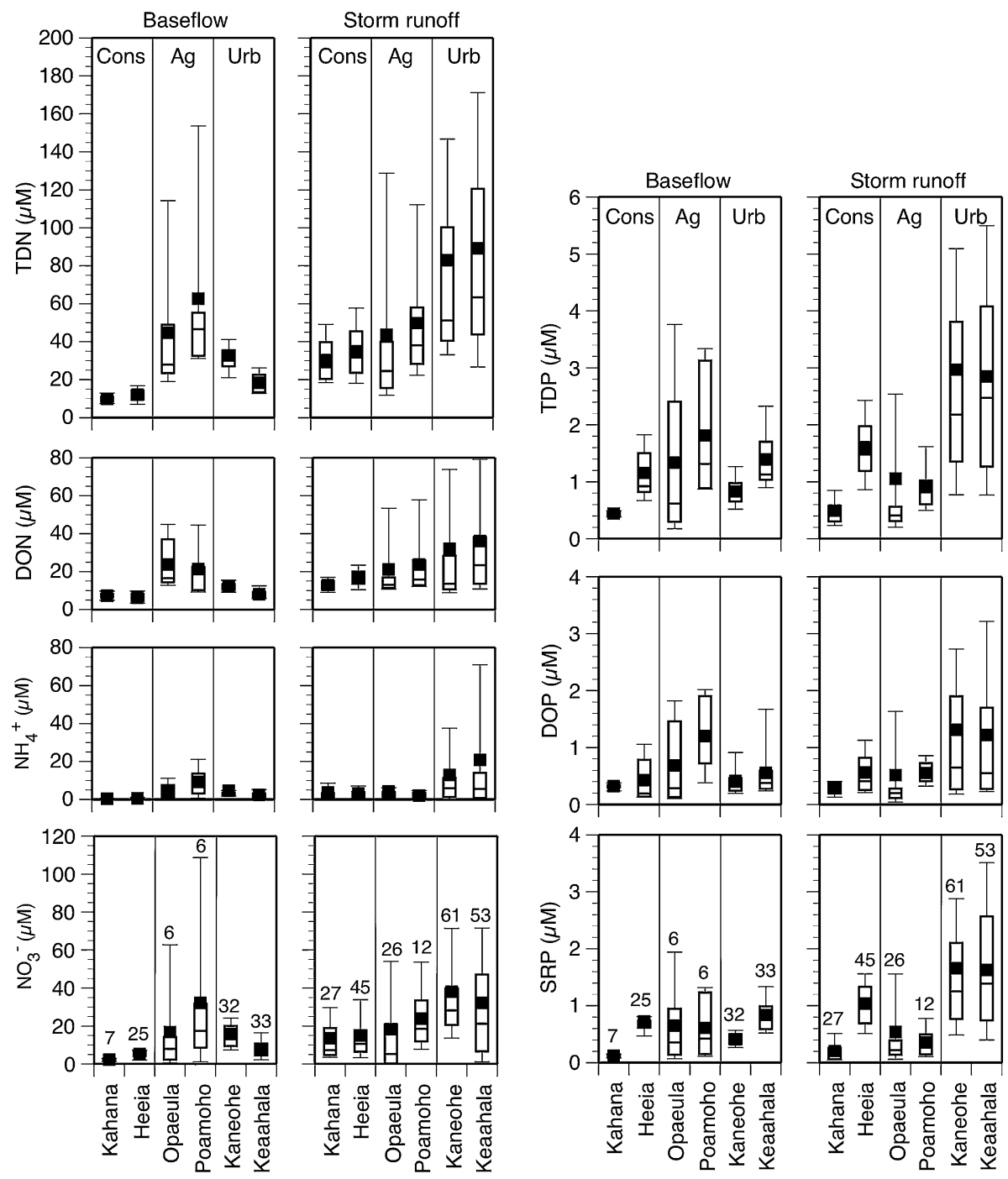

Fig. 8 Boxplots of dissolved nitrogen and phosphorus concentrations in baseflow and storm runoff samples. Boxes denote values from 25 th to 75 th percentile, lines extend to 10th and 90th percentiles. Line in the box is the median, solid square is the mean. Numbers in lower panels are numbers of samples analyzed

discharged (Fig. 9). For POC and PON, low-flow samples had higher and more variable concentrations than storm runoff samples, and storm runoff samples exhibited gradual but tightly coupled exponential declines with increasing flow. Declining trends were also seen in particulate phosphorus parameters at several sites, but were not always linked clearly to the corresponding POC and PON trends. In particular, POP concentrations at most sites exhibited little or no flow dependency. Particle quality was also correlated with land use; differences between low- and high-flow SPM quality were more pronounced at conservation and agricultural sites than at urban sites, and POC, PON, and POP in high-flow samples were highest at conservation sites, intermediate at urban sites, 
Table 2 Median dissolved nitrogen and phosphorus concentrations $(\mu \mathrm{M})$ in baseflow $(\mathrm{B})$ and storm runoff (S) samples

\begin{tabular}{|c|c|c|c|c|c|c|c|c|c|c|c|c|c|c|c|c|}
\hline \multirow[t]{2}{*}{ Site } & \multicolumn{2}{|c|}{$\mathrm{NO}_{3}^{-}$} & \multicolumn{2}{|c|}{$\mathrm{NH}_{4}{ }^{+}$} & \multicolumn{2}{|c|}{ DON } & \multicolumn{2}{|l|}{ TDN } & \multicolumn{2}{|l|}{ SRP } & \multicolumn{2}{|c|}{ DOP } & \multicolumn{2}{|l|}{ TDP } & \multicolumn{2}{|c|}{$\mathrm{N}_{\mathrm{r}} / \mathrm{P}_{\mathrm{r}}$} \\
\hline & B & $\mathrm{S}$ & B & S & B & $S$ & B & $\mathrm{S}$ & B & $S$ & B & S & B & $S$ & $\mathrm{~B}$ & $S$ \\
\hline Kahana (C) & 2.2 & 7.2 & 0.28 & 1.2 & 7.1 & 13 & 9.8 & 26 & 0.12 & 0.12 & 0.33 & 0.29 & 0.45 & 0.47 & 21 & 70 \\
\hline Heeia (C) & 4.8 & 11 & 0.34 & 2.5 & 5.4 & 16 & 11 & 32 & 0.70 & 0.98 & 0.19 & 0.43 & 0.92 & 1.5 & 7 & 14 \\
\hline Opaeula (A) & 7.9 & 5.2 & 2.2 & 1.1 & 16 & 13 & 28 & 25 & 0.36 & 0.22 & 0.28 & 0.20 & 0.62 & 0.40 & 28 & 29 \\
\hline Poamoho (A) & 18 & 18 & 8.1 & 1.5 & 20 & 16 & 47 & 38 & 0.42 & 0.28 & 1.1 & 0.46 & 1.3 & 0.84 & 62 & 70 \\
\hline Kaneohe (U) & 15 & 28 & 2.6 & 5.9 & 12 & 14 & 31 & 51 & 0.41 & 1.2 & 0.31 & 0.65 & 0.77 & 2.2 & 43 & 28 \\
\hline Keaahala (U) & 6.0 & 21 & 1.9 & 5.6 & 7.3 & 23 & 17 & 63 & 0.79 & 1.4 & 0.38 & 0.55 & 1.1 & 2.5 & 10 & 19 \\
\hline
\end{tabular}

Differences in baseflow versus storm runoff concentrations were tested using $t$-tests on log-transformed concentrations; results with $P$-values $\leq .05$ are highlighted. Reactive nitrogen $\left(\mathrm{NO}_{3}{ }^{-}+\mathrm{NH}_{4}{ }^{+}\right)$to phosphorus (SRP) ratios $\left(\mathrm{N}_{\mathrm{r}} / \mathrm{P}_{\mathrm{r}}\right)$ also are shown; values $>30$ are in bold, values $<10$ are in italics

$C$ conservation, $A$ agriculture, $\mathrm{U}$ urban
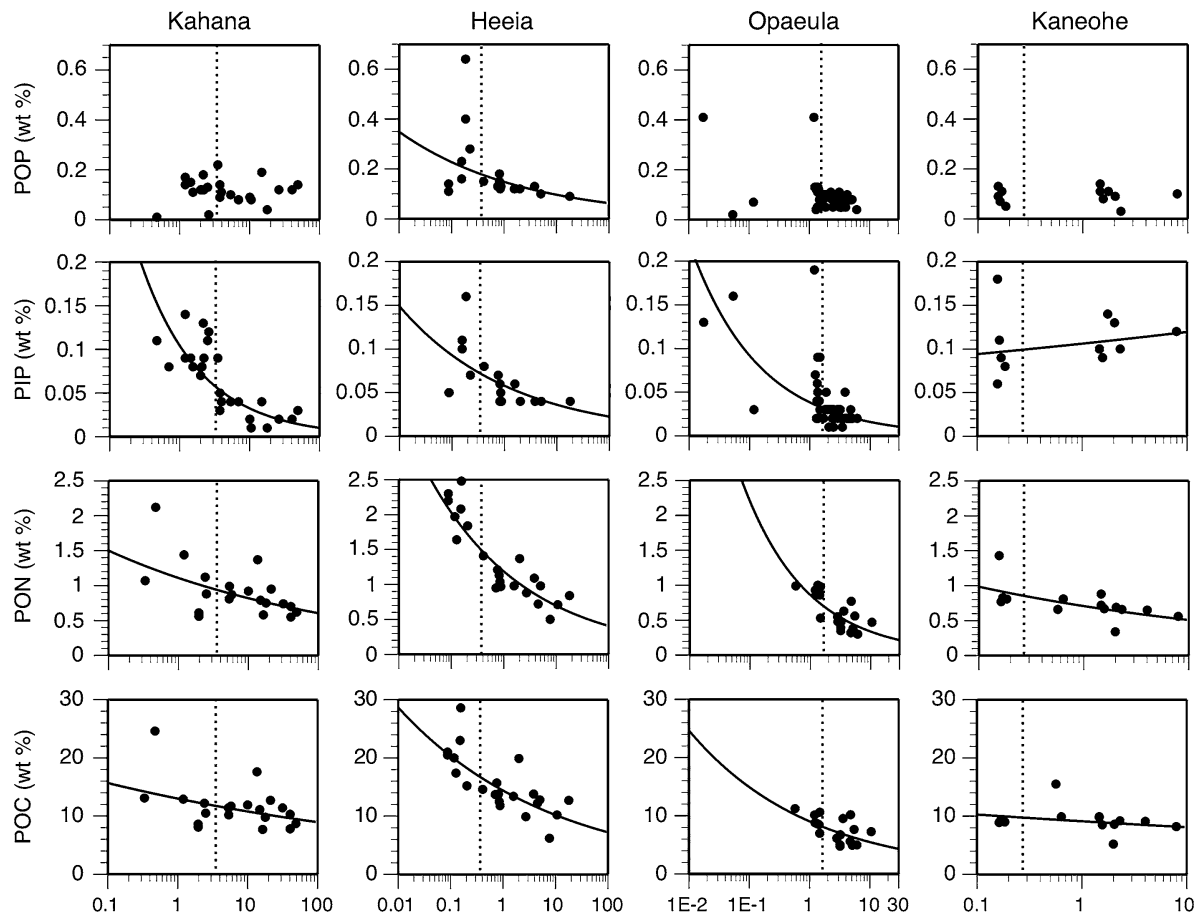

Runoff $\left(\mathrm{cm} \mathrm{d}^{-1}\right)$

Fig. 9 Particulate $\mathrm{C}, \mathrm{N}$, and $\mathrm{P}$ at sites with quantitative flow data. Exponential regression fits are shown where the fit explains more than $5 \%$ of the variability in the data. Dashed vertical line is particulate low/high runoff break at each site

and lowest at agricultural sites (Fig. 10, Table 3). PIP in high-flow samples followed a different pattern with high levels at urban sites and low values at conservation and agricultural sites. 

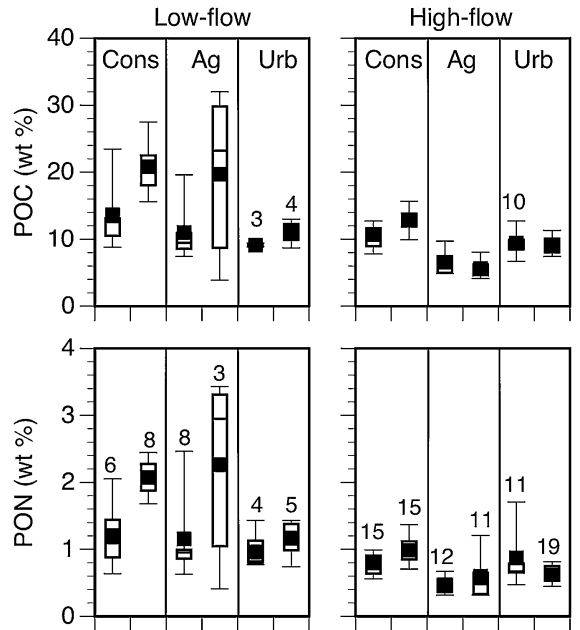

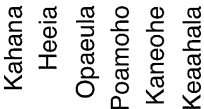

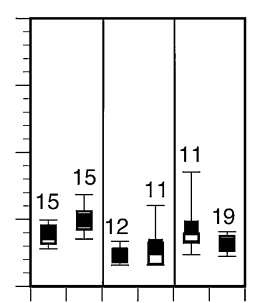

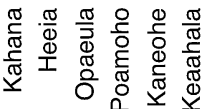
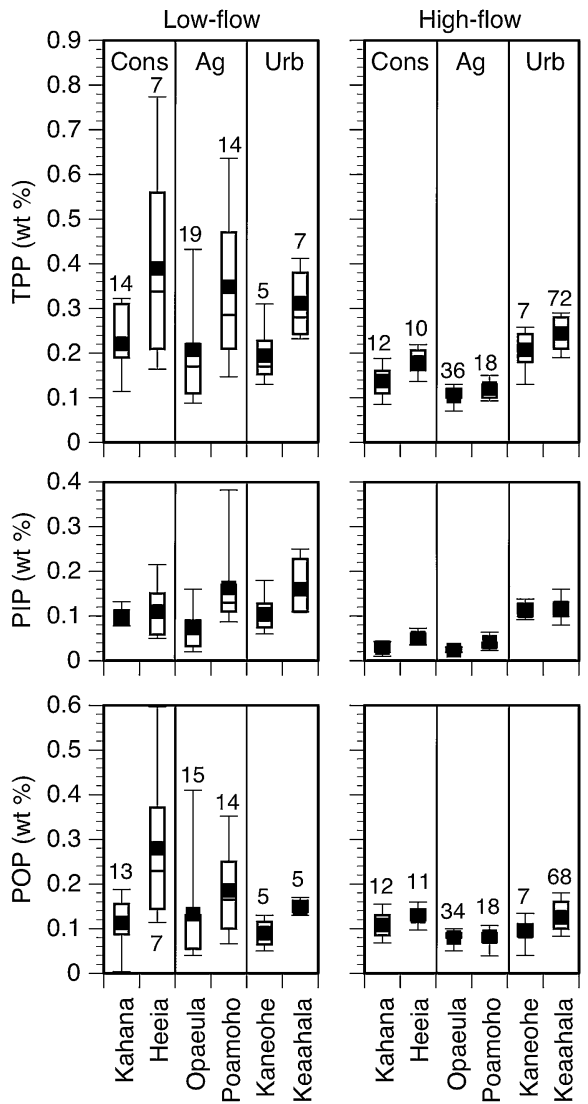

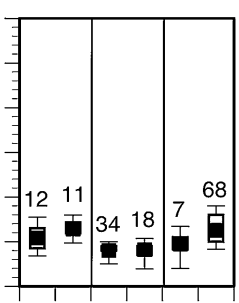

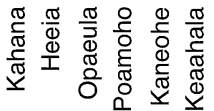

Fig. 10 Particulate carbon, nitrogen and phosphorus in low- and high-flow samples at study sites. Boxes denote values from 25 th to 75 th percentile, lines extend to 10th and 90th percentiles. Line in the box is the median, solid square is the mean. Numbers in panels are numbers of samples analyzed

Table 3 Median particulate organic carbon, nitrogen, and phosphorus concentrations in suspended particulate matter (SPM) in baseflow (B) and storm runoff (S) samples

\begin{tabular}{|c|c|c|c|c|c|c|c|c|c|c|}
\hline \multirow[t]{2}{*}{ Site } & \multicolumn{2}{|c|}{ POC } & \multicolumn{2}{|l|}{ PON } & \multicolumn{2}{|l|}{ PIP } & \multicolumn{2}{|l|}{ POP } & \multicolumn{2}{|l|}{ TPP } \\
\hline & B & $\mathrm{S}$ & B & $\mathrm{S}$ & B & $S$ & B & $S$ & B & $\mathrm{S}$ \\
\hline Kahana (C) & 13 & 10 & 1.1 & 0.75 & 0.090 & 0.030 & 0.12 & 0.10 & 0.22 & 0.14 \\
\hline Heeia (C) & 20 & 13 & 2.1 & 0.98 & 0.096 & 0.036 & 0.23 & 0.13 & 0.34 & 0.18 \\
\hline Opaeula (A) & 9.5 & 6.1 & 0.96 & 0.48 & 0.060 & 0.020 & 0.12 & 0.080 & 0.17 & 0.10 \\
\hline Poamoho (A) & 23 & 5.1 & 3.0 & 0.48 & 0.13 & 0.040 & 0.16 & 0.085 & 0.28 & 0.12 \\
\hline Kaneohe (U) & 9.0 & 9.2 & 0.82 & 0.67 & 0.090 & 0.10 & 0.090 & 0.10 & 0.17 & 0.22 \\
\hline Keaahala (U) & 11 & 8.6 & 1.2 & 0.59 & 0.11 & 0.11 & 0.14 & 0.13 & 0.28 & 0.24 \\
\hline
\end{tabular}

All values are expressed as weight percent of SPM. Differences in baseflow versus storm runoff concentrations were tested using $t$-tests on log-transformed concentrations; results with $P$-values $\leq .05$ are highlighted

$C$ conservation, $A$ agriculture, $U$ urban 


\subsection{Nutrient Yields}

Dissolved and particulate nutrient yields (Fig. 11) largely follow the interannual patterns established for water and SPM yields, respectively, with relatively high yields in 1997 dropping dramatically in 1998 and recovering to intermediate values in 1999 and 2000. Total $\mathrm{N}$ and $\mathrm{P}$ yields covaried between years at each site, reflecting the dominant role of
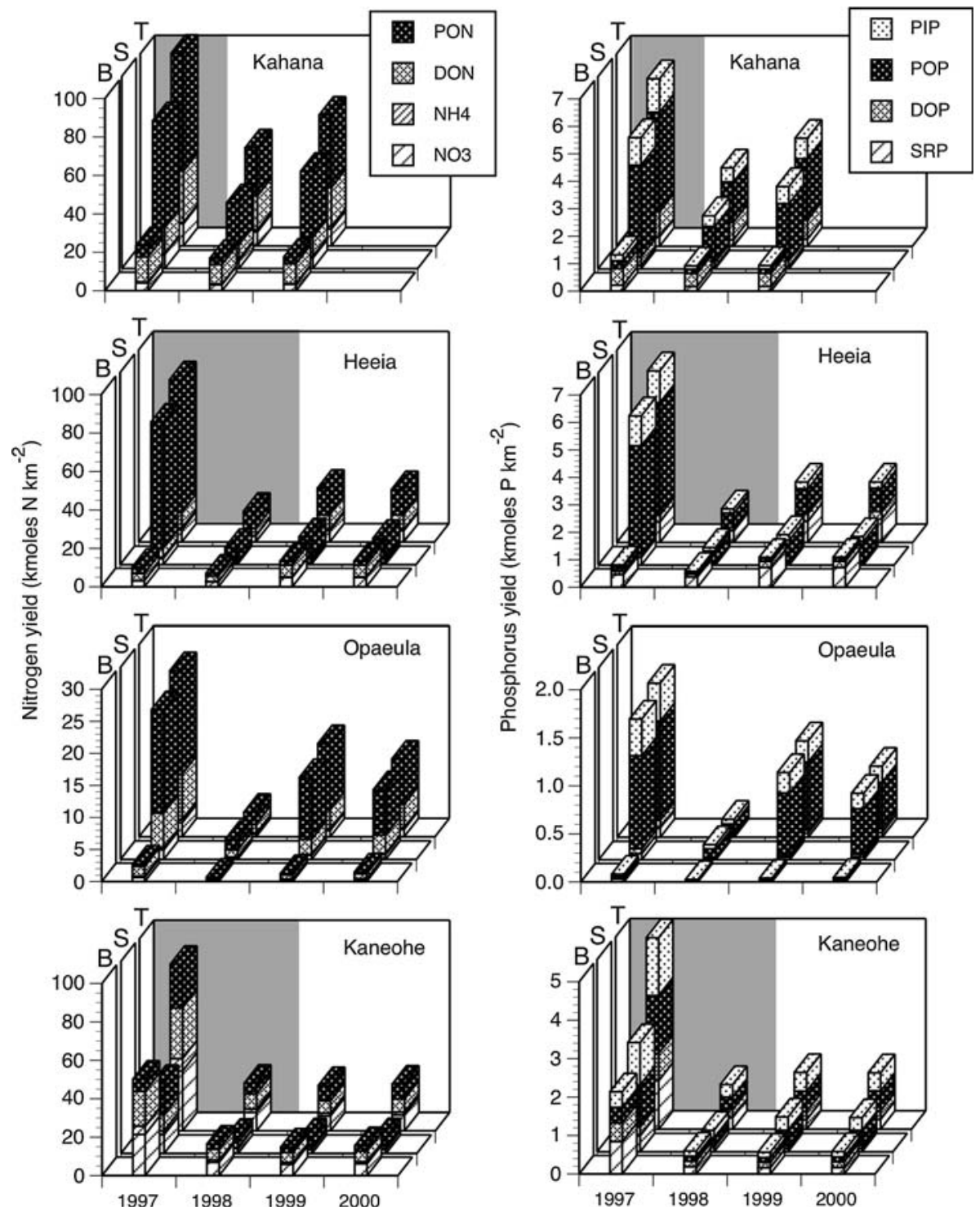

Fig. 11 Annual nitrogen (left panels) and phosphorus (right panels) yields at study sites with quantitative flow data. Yields are separated along the depth axis into baseflow (B), storm runoff (S) and total (T) yields. Years where data are estimated primarily using USGS discharge data have gray backgrounds 
storms in annual SPM yields and associated PON and POP fluxes. PIP was also a significant component of total $\mathrm{P}$ yields at all sites. Comparison across sites shows that the most reactive constituents (nitrate, ammonia, and SRP) were relatively more important at the Heeia and Kaneohe sites, where they contributed up to $40 \%$ of total yields, but that these constituents represented less than $10 \%$ of total yields at the Kahana and Opaeula sites. DON and DOP yields varied in importance relative to particulate and dissolved inorganics, but generally were comparable to inorganic yields.

\section{Discussion}

Despite the reduced storm frequency and intensity during the study period, storms were responsible for the majority of SPM and particulate nutrient fluxes, and contributed significantly to water and dissolved nutrient fluxes, in all study streams. Annual storm runoff varied widely from year to year and between sites, contributing 8-77\% (median 30\%) of water fluxes, 11-79\% (median 36\%) of dissolved nutrient fluxes, 57-99\% (median 93\%) of SPM fluxes, and 52-99\% (median 85\%) of particulate nutrient fluxes. These results were obtained during years characterized by unusually dry conditions (1998) and below-normal rainfall (1999 and 2000) with only one year of relatively typical rainfall and storm activity (1997), indicating that during more typical climatic conditions, and over longer time periods, storms would be even more important. Much of the interannual difference and some of the between-site differences can be attributed to variability in the frequency and intensity of storms, but most of the differences between sites are due to differences in watershed characteristics, including land use effects on runoff and particle transport. Storm fluxes at all sites were highly episodic and short-lived with storm runoff conditions occurring less than $10 \%$ of the time. As a result, stream fluxes occurred as relatively long periods of stable baseflow fluxes interrupted by brief but intense increases in water, SPM, and dissolved and particulate nutrient fluxes during storm events. Storms were very important to annual fluxes of water, SPM, and associated nutrients, and were the major source of temporal variability in stream fluxes.

Urban and agricultural land use both appear to impact fluvial fluxes in Oahu streams, but quantitative assessments of land use impacts on runoff are complicated by the need to adjust for differences in rainfall in different watersheds, and by natural factors affecting runoff. Rainfall data are not available in our study watersheds specifically for study years, but median rainfall can be used with our runoff data from 1997, a relatively typical year, to examine differences between watersheds (Table 4). The runoff/rainfall ratio of 0.63 for Kahana Stream seems likely to be close to an upper limit for Oahu streams, as the headwaters of the stream are located in the wettest part of the island (Fig. 1), and discharges from Kahana Stream typically are exceeded on Oahu only by discharges from Waikele Stream, which drains a much larger watershed directly opposite to the Kahana watershed on the leeward side of the Koolau mountains (e.g., Hill et al. 1998). Runoff and

Table 41997 runoff normalized to median annual rainfall in study watersheds

$C$ conservation, $A$ agriculture, $U$ urban

\begin{tabular}{lllll}
\hline & Kahana (C) & Heeia (C) & Opaeula (A) & Kaneohe (U) \\
\hline Runoff $(\mathrm{cm})$ & 289 & 96.5 & 37.7 & 137 \\
Rainfall $(\mathrm{cm})$ & 458 & 235 & 323 & 204 \\
Runoff/rainfall & 0.63 & 0.41 & 0.12 & 0.67 \\
\hline
\end{tabular}


rainfall in the adjacent Heeia and Kaneohe watersheds should be rather similar; the greater runoff/rainfall ratio in the Kaneohe watershed thus must reflect land use related differences. Urban development commonly enhances runoff by increasing the amount of impervious surfaces in watersheds, which would increase the runoff/rainfall ratio. However, other land use factors probably also are important in the Kaneohe watershed. For example, runoff in the Kaneohe watershed showed much larger declines in low runoff years than were observed at the conservation sites (Fig. 4). This phenomenon can be explained by runoff retention and enhanced evaporation in a flood-control reservoir upstream of the monitoring site. Accumulation of storm flows in the reservoir also reduces peak flows downstream of the reservoir and extends the duration of storm flows (Fig. 3). Conversely, discharges from the reservoir between storms increase and stabilize baseflows. Land use factors thus have a number of impacts on runoff at this site. The very low runoff/rainfall ratio of the Opaeula site $(0.12)$ results in part from diversion of a portion of base and storm flows for irrigation (c.f., Hill et al. 1998). It is likely that cultivation in the watershed also affects overland flow, evaporation, and infiltration, but the relative importance of these factors cannot be evaluated without additional data. Natural factors also play an important role in the low runoff/rainfall ratio at this site, as the majority of the Opaeula watershed receives very little rainfall (Fig. 1), and loss terms (evaporation, diversions, and recharge of long-term groundwater) play a disproportionately large role in the hydrologic budget, reducing the runoff/rainfall ratio. Overall, while land use probably does affect runoff in the Opaeula watershed, natural factors seem likely to be as or more important.

While our data show some evidence of land use effects on runoff, quantifying land use effects may be difficult in Hawaiian watersheds due to the extreme variability in natural factors affecting runoff. For instance, runoff values from our study watersheds fall within the range of values observed for other small tropical island watersheds in Hawai' $i$ and Puerto Rico (Hoover 2002), but the range is large with the Kahana watershed (230 $\mathrm{cm} \mathrm{y}^{-1}$ ) near the top of the Hawai' $i$ range, and the Opaeula watershed $\left(20 \mathrm{~cm} \mathrm{y}^{-1}\right)$ at the bottom. Clearly, much of this difference is due to natural factors such as rainfall, which varies dramatically over very short distances on small mountainous tropical islands, instead of land use. Watersheds in Hawai' $i$ and on other small tropical islands may also have a fundamentally different hydrological response to rainfall than watersheds in other areas. For instance, comparing Hawai 'i and Puerto Rico watersheds to Milliman and Syvistski's (1992) global dataset shows that Hawai'i and Puerto Rico watersheds exhibit relatively low runoff for their size (Hoover 2002).

Our data do allow us to address the effect of the flood-control reservoir in the Kaneohe watershed on SPM fluxes. Not surprisingly, storm SPM fluxes decreased dramatically after reservoir installation due to sediment trapping in the reservoir. Over the range of storm flows sampled in this study (up to $\sim 10 \mathrm{~m}^{3} \mathrm{~s}^{-1}$ ), storm SPM concentrations downstream of the reservoir were roughly two-fold higher before reservoir construction (Dugan 1977), consistent with the $71 \%$ sediment trapping efficiency estimated for the reservoir (Wong 2001). Historical baseflow SPM data are not available, but it seems likely that reservoir construction also enhanced baseflow SPM concentrations. Increased baseflow and reduced flow variation downstream of the reservoir should increase in-stream primary and secondary production, and some portion of the SPM produced in the reservoir (i.e., phytoplankton and organic detritus) is exported in reservoir outflow. Both reservoir and in-stream production also should be enhanced by nutrients released from sediments trapped in the reservoir.

At the Opaeula site, historical SPM data are less extensive, but the generally higher SPM concentrations observed prior to the demise of sugar cane cultivation (DeVito 1993) 
suggest that agricultural activity had increased particle fluxes from the watershed. This interpretation is supported by SPM yields from an uncultivated watershed adjacent to the Opaeula watershed that were 4- to 5-fold lower than yields from the Opaeula watershed (DeVito 1993). While these data indicate a potential agricultural land use impact on particle fluxes, it is noteworthy that SPM yields from study watersheds were low compared to yields from other Hawaiian watersheds with comparable runoff and watershed areas, and that yields from Hawaiian watersheds in general plot well below global trends for watersheds with comparable maximum elevations (Hoover 2002). Some of the difference is likely due to the relatively short yield records available at many Hawaii sites, as SPM yields from Hawaiian watersheds commonly show strong exponential increases with runoff (cf., Fig. 5). Rare large runoff events in these watersheds produce very large SPM yields that substantially increase long-term averages (Hoover 2002). However, inclusion of even very rare/large SPM flux events appears unlikely to be able to account for all of the difference, nor does the inclusion of the additional lithological, soil erosion, and reservoir trapping parameters suggested by Syvistski and Milliman (2007), suggesting that Hawaii's watersheds may have unique attributes not yet captured in global parameterizations of SPM flux.

Land use changes affect dissolved nutrient fluxes partly by impacting runoff, but changes in nutrient concentrations are as or more important at most sites. Runoff at urban sites consistently had elevated concentrations of dissolved nitrogen and phosphorus in both baseflow and storm runoff, and most dissolved constituents were also elevated in runoff from agricultural watersheds. In the Kaneohe watershed, historical data from a site just upstream of our study site (Dugan 1977) overlap remarkably well with our data, but differences in silica concentrations (higher in historical baseflow samples) and higher nitrate, ammonia, and DOP concentrations in our intermediate- and high-flow samples show that reservoir construction did affect concentrations of dissolved species. For silica, the retention of water in the reservoir should enhance silica uptake by diatoms, and resuspension of reservoir sediments and associated porewaters during storms could be responsible for the observed increases in dissolved $\mathrm{N}$ and $\mathrm{P}$. However, close agreement between our Opaeula nitrate, ammonia, and SRP data and data collected prior to the end of sugar cane cultivation (DeVito 1993) shows that concentrations at this site were not affected dramatically by the cessation of agricultural activity, although our agricultural sites in general had different characteristic dissolved nutrient concentrations than our urban and conservation sites (Fig. 8, Table 2). On a global scale, nutrient concentrations at our conservation sites are rather similar to concentrations from the 'pristine' streams summarized in Meybeck (1982), and the elevated nutrient concentrations observed at our urban and agricultural sites are modest compared to levels in polluted rivers (Meybeck and Ragu, unpublished data, Hoover 2002).

For particulate nutrient fluxes, land use related changes in SPM fluxes were much more important in controlling total fluxes than changes in SPM quality, especially at the Kaneohe site where storm SPM fluxes were reduced by roughly a factor of two and baseflow SPM fluxes were much higher than at any other study site. However, changes in particle quality were also important, particularly in storm SPM where PON and POP were highest at conservation sites, similar or slightly lower at urban sites, and lowest at agricultural sites (Fig. 10). This pattern is consistent with numerous studies that have documented reductions in organic material in cultivated soils (Schlesinger 1997). PIP in storm SPM was also strongly related to land use with much higher values at urban sites than at conservation or agricultural sites (Fig. 10), although the reason for the increase at urban sites is not known. 
Overall, land use was associated with significant changes in fluvial fluxes at our study sites, particularly SPM, particulate nutrients and water at Kaneohe, SPM and particulate nutrients at Opaeula, and with more modest changes in dissolved nutrient fluxes at both sites. These changes result in relatively subtle changes in the timing and form of dissolved nutrient delivery to coastal waters, but more dramatic changes in SPM and particulate nutrient inputs. The impacts of these changes on coastal ecosystems will depend both on the severity of the change and on the constituent affected (Redfield et al. 1963; Dugdale and Goering 1967; Björkman and Karl 1994; Dollar and Andrews 1997). Changes in the quantity and timing of baseflow and storm runoff inputs alter the frequency and duration of exposure of marine organisms to freshwater stress, which will affect the abundance and types of mixohaline organisms around stream mouths (Banner 1968; Jokiel et al. 1993), and impact marine organisms that respond to freshwater cues, such as endemic Hawaiian anadromous gobies. Changes in SPM loads to coastal waters will alter the distribution of organisms sensitive to both the direct effects of SPM loading and to indirect effects such as turbidity [e.g., corals (Richmond 1993)], and of organisms that utilize SPM as a food source. Changes in SPM physical properties (e.g., particle size, density, optical characteristics) may also affect nearshore ecosystems through changes in particle settling rates and SPM contributions to turbidity. Particulate loading frequently is cited as detrimental to coastal ecosystems, and excessive loading has resulted in degradation of nearshore ecosystems in some areas in Hawai'i (EPA 1971; Lau 1972; Stamski 2003). However, fluvial SPM inputs are a natural occurrence at many locations along Hawaii's coastline, suggesting that coastal ecosystems in these areas are adapted to SPM inputs, and in some cases may depend on them for food or for inorganic nutrients released from SPM (e.g., Martens 1978; Sundby et al. 1992; Berner and Rao 1994; Ruttenberg and Canfield 1994). In these areas, reductions in SPM loading such as those observed in this study in the Kaneohe watershed may negatively affect coastal ecosystems.

Increases in dissolved nutrient inputs could increase the productivity of coastal ecosystems, particularly in the water column where increased nitrogen concentrations can help to relieve the nitrogen limitation frequently observed in coastal waters in Hawai ' $\mathrm{i}$ (Smith et al. 1981; Laws and Redalje 1982; Laws and Allen 1996; DeCarlo et al. 2007; Hoover unpublished data). Changes in the relative proportions of dissolved nutrients can also affect community structure, as organisms differ in their abilities to take up and process different inorganic and organic constituents. Dissolved nutrients are likely to be taken up most efficiently under baseflow conditions when freshwater inputs occur at low but steady rates. Although storms result in large inputs of dissolved nutrients to coastal waters, inputs occur as large pulses and storm conditions frequently are unfavorable for nutrient uptake [e.g., low light due to cloud cover and elevated turbidity, rapid mixing of plumes into lownutrient coastal waters by wind and waves (Ostrander et al. 2008) resulting in dilution of nutrients], so changes in storm fluxes of dissolved nutrients may not impact coastal ecosystems as much as changes in baseflow fluxes. When storm plumes persist for extended periods, elevated nitrogen concentrations can support phytoplankton and zooplankton blooms (Ringuet and Mackenzie 2005; Hoover et al. 2006), and the increased SRP concentrations found in urban runoff might extend bloom durations for longer periods than would otherwise be observed (e.g., Ringuet and Mackenzie 2005). In addition to sequestering terrestrial nutrients in nearshore biota, these blooms can also affect water column chemistry, for instance by drawing down $\mathrm{CO}_{2}$ in surface waters (Fagan and Mackenzie 2007; Paquay et al. 2007). However, for both baseflow and storm runoff conditions, changes in dissolved nutrient inputs are unlikely to have much impact on benthic communities as inputs would need to be diluted to near-marine salinities to reach the benthos, 
and nutrient concentrations in bottom waters often already are elevated due to remineralization of detritus in coastal sediments.

Changes in particulate nutrient fluxes will impact coastal ecosystems where SPM is a food source for heterotrophs, or where particulate nutrients are an important source of dissolved nutrients (via remineralization or desorption) for primary producers. The latter scenario is likely to be most important in areas where SPM is retained efficiently in nearshore areas. For instance, nutrient-budget analyses have shown that SPM could be a major source of new nutrients to southern Kaneohe Bay (Hoover 2002).

The contribution of particulate nutrients to coastal nutrition ultimately depends on how rapidly and to what extent particulate forms are converted to dissolved forms, so changes in the quality of the organic material in SPM that affect the rate and degree of remineralization will also impact these ecosystems. While there appear to be only small differences in particle quality between our conservation, urban, and agricultural sites (Fig. 10), reductions in particle quality probably occur primarily via depletion of the most labile constituents, so land use changes that reduce particle quality only a small amount actually may have large impacts on nutrient availability in coastal ecosystems. Where coastal waters are nitrogen limited, impacts will be particularly important if labile particulate nitrogen is depleted, but changes in particulate phosphorus could also have impacts where coastal waters are co-limited by $\mathrm{N}$ and $\mathrm{P}$, or where nutrient status changes with time, such as following storm runoff events where conditions can switch from nitrogen to phosporus limitation (Ringuet and Mackenzie 2005). Particulate nutrient fluxes thus seem likely to be at least as important as dissolved nutrient fluxes for many Hawaiian coastal ecosystems, and land use related reductions in particulate nutrient fluxes actually may have negative impacts on some coastal ecosystems, rather than the positive impacts often assumed.

\section{Conclusions}

This study quantified the relative contributions of storm runoff and baseflow to water, SPM and nutrient fluxes to Oahu coastal waters, and the effects of agricultural and urban land use on water and SPM quality and associated nutrient fluxes. Storms played a major role in water, SPM, and nutrient fluxes at all sites despite unusually low storm frequency and intensity during much of the study period, indicating that storms likely play an even greater role during more typical periods. Land use had significant effects on water and SPM quality, water, and SPM fluxes, and on the contribution of storms to overall fluxes. In Hawai' $i$, the combination of intermittent (and often intense) storm discharges, relatively stable baseflow discharges, and land use related variations in water and SPM fluxes and quality results in temporally and spatially varying inputs of terrestrial nutrients to coastal waters. The impacts of these inputs on coastal ecosystems depend on the reactivity of individual constituents and on their retention in coastal waters, and impacts are likely to be very different for dissolved and particulate nutrients. Dissolved inorganic nutrients are delivered in ratios favorable for phytoplankton growth, but storm inputs often are diluted and exported rapidly resulting in the loss of a large fraction of the storm pulse. Particulate nutrient fluxes can be comparable to or larger than dissolved fluxes, but particulate nutrients are likely to be less biologically 'available' than dissolved nutrients on short timescales. However, where SPM is retained in nearshore waters, remineralization, and desorption reactions could provide significant nutrient subsidies over long (weeks to years) time scales. Because both dissolved and particulate nutrient inputs may be important for some coastal ecosystems, efforts to manage dissolved and particulate fluxes from watersheds should consider both positive and negative 
impacts of fluvial fluxes. A complete understanding of the impacts of fluvial fluxes on coastal ecosystems in Hawai'i will require characterization of input functions, including land use effects on the timing and form of water, SPM, and nutrient fluxes, and of processes affecting nutrient uptake and retention in coastal waters and sediments. As storms dominate total nutrient inputs to coastal waters, it is particularly important to characterize the reactivity and retention of storm-derived nutrients, especially particulate $\mathrm{N}$ and $\mathrm{P}$, and their impacts on coastal ecosystems.

Acknowledgments We thank S. Smith, E. DeCarlo, R. Kinzie, C. Smith, R.S. Hoover, K. Ruttenberg, B. Sundby and 3 anonymous reviewers for their helpful comments on earlier versions of this manuscript. We also thank D. Hashimoto and T. Rust for their assistance in the analysis of nutrient samples, and the U.S. Geological Survey, the U.S. Coast Guard, Castle and Cooke, Dole Foods, the State of Hawai 'i, Kauhale Beach Cove Condominiums, and Paul Jacoby and Barbara Lynn for access to study sites. This study was funded in part by a grant/cooperative agreement from the National Oceanic and Atmospheric Administration, project R/El 33, which is sponsored by the University of Hawaii Sea Grant College Program, SOEST, under Institutional Grant No. NA05OAR417048 from the NOAA Office of Sea Grant, Department of Commerce. The views expressed herein are those of the authors and do not necessarily reflect the views of NOAA or any of its subagencies. Contribution No. 7772 from the School of Ocean and Earth Science and Technology, University of Hawai' $i$ at Manoa.

Open Access This article is distributed under the terms of the Creative Commons Attribution Noncommercial License which permits any noncommercial use, distribution, and reproduction in any medium, provided the original author(s) and source are credited.

\section{References}

American Public Health Association, American Water Works Association, Water Pollution Control Federation (1995) Standard methods for the examination of water and wastewater. American Public Health Association, Washington

Armstrong FAJ, Tibbits S (1968) Photochemical combustion of organic matter in sea water for nitrogen, phosphorus and carbon determination. J Mar Biol Assoc UK 48:143-152

Aspila KI, Agemian H, Chau ASY (1976) A semi-automatic method for the determination of inorganic, organic and total phosphate in sediments. Analyst 101:187-197

Banner AH (1968) A freshwater "kill" on Hawaiian coral reefs. University of Hawaii, HIMB, Honolulu

Berner RA, Rao J-L (1994) Phosphorus in sediments of the Amazon river and estuary: implications for the global flux of phosphorus to the sea. Geochim Cosmochim Acta 58(10):2333-2339

Björkman K, Karl DM (1994) Bioavailability of inorganic and organic phosphorus compounds to natural assemblages of microorganisms in Hawaiian coastal waters. Mar Ecol Prog Ser 111:265-273

Cheng EDH, Lau LS (1973) Some statistical analyses of Hawaiian rainfall. Water Resources Research Center, Honolulu, 63 pp

DeCarlo EH, Hoover DJ, Young CW et al (2007) Impact of storm runoff from tropical watersheds on coastal water quality and productivity. Appl Geochem 22(8):1777-1797

DeVito PJ (1993) Nonpoint source pollution within the Kaiaka-Waialua watershed. M.S. Thesis, University of Hawaii

Dollar S, Andrews C (1997) Algal blooms off West Maui: assessing causal linkages between land and the coast ocean. Final report, SOEST, University of Hawaii, Manoa. Honolulu, 101 pp

Dugan GL (1977) Water quality of normal and storm-induced surface water runoff: Kaneohe Bay watershed, Oahu, Hawaii, February 1974 to March 1975. University of Hawaii Water Resources Research Center, Honolulu

Dugdale RC, Goering JJ (1967) Uptake of new and regenerated forms of nitrogen in primary productivity. Limnol Oceanogr 12(2):196-206

EPA U. S. (1971) The Hawaii sugar industry waste study. U.S. Environmental Protection Agency, Washington

Fagan KE, Mackenzie FT Air-sea $\mathrm{CO}_{2}$ exchange in a subtropical estuarine-coral reef system, Kaneohe Bay, Oahu, Hawaii, USA. Marine Chemistry 106:174-191 
Fox RL, Searle PGE (1978) In: Drosdoff M, Daniels RB, Nicholaides JJIII (eds) Phosphate adsorption by soils of the tropics. Diversity of soils in the tropics. ASA, SSSA, Madison, pp 97-119

Gavenda R, Smith C, Vollrath N (1998) In: Juvik SP, Juvik JO (eds) Soils. Atlas of Hawaii. University of Hawaii Press, Honolulu, pp 92-96

Hill BR (1996) Streamflow and suspended-sediment loads before and during highway construction, North Halawa, Haiku, and Kamooalii drainage basins, Oahu, Hawaii, 1983-91. U.S. Geological Survey, Honolulu, p 34

Hill BR, Taogoshi RI, Kunishige VE et al (1998) Water resources data Hawaii: water year 1997. U.S. Geological Survey, Honolulu

Hoover DJ (2002) Fluvial nitrogen and phosphorus in Hawaii: storm runoff, land use, and impacts on coastal waters. Department of Oceanography, University of Hawaii, Honolulu, p 437

Hoover RS, Hoover DJ, Miller M et al (2006) Zooplankton response to storm runoff in a tropical estuary: bottom-up and top-down controls. Mar Ecol Prog Ser 318:187-201

Hufen TH, Eyre P, McConachie W (1980) Underground residence times and chemical quality of basal groundwater in Pearl Harbor and Honolulu aquifers, Oahu, Hawaii. University of Hawaii, Water Resources Research Center, Honolulu

Jokiel PL, Hunter CL, Taguchi S et al (1993) Ecological impact of a fresh-water "reef kill” in Kaneohe Bay, Oahu, Hawaii. Coral Reefs 12:177-184

Kotlash AR, Chessman BC (1998) Effects of water sample preservation and storage on nitrogen and phosphorus determinations: implications for the use of automated sampling equipment. Water Res 32(12):3731-3737

Lau LS (1972) The quality of coastal waters: first annual progress report. Water Resources Research Center, Honolulu

Laws EA, Allen CB (1996) Water quality in a subtropical embayment more than a decade after diversion of sewage discharges. Pac Sci 50(2):194-210

Laws EA, Redalje DG (1982) Sewage diversion effects on the water column of a subtropical estuary. Mar Environ Res 6:265-279

Mackenzie FT (2003) Our changing planet. Upper Saddle River, Prentice Hall

Martens CS (1978) Interstitial water chemistry of anoxic Long Island sound sediments. 2. Nutrient regeneration and phosphate removal. Limnol Oceanogr 23(4):605-617

Meybeck M (1982) Carbon, nitrogen, and phosphorus transport by world rivers. Am J Sci 282:401-450

Milliman JD, Syvitski JPM (1992) Geomorphic/tectonic control of sediment discharge to the ocean: The importance of small mountainous rivers. J Geol 100:525-544

Monaghan EJ, Ruttenberg KC (1999) Dissolved organic phosphorus in the coastal ocean: reassessment of available methods and seasonal phosphorus profiles from the Eeel River Shelf. Limnol Oceanogr 44(7):1702-1714

Ostrander CE, McManus MA, DeCarlo EH, MacKenzie FT (2008) Temporal and spatial variability of freshwater plumes in a semi-enclosed estuarine-bay system. Estuaries and Coasts. 31:192-203

Paquay FS, Mackenzie FT, Borges AV (2007) Carbon dioxide dynamics in rivers and coastal waters of the "Big Island" of Hawaii, USA, during baseline and heavy rain conditions. Aquat Geochem 13:1-18

Redfield AC, Ketchum BH, Richards FA (1963) The influence of organisms on the composition of seawater. In: Hill MN (ed) The sea, vol 2. Wiley, New York, pp 26-77

Richmond RH (1993) Coral reefs: present problems and future concerns resulting from anthropogenic disturbance. Am Zoologist 33:524-536

Ridal JJ, Moore RM (1990) A re-examination of the measurement of dissolved organic phosphorus in seawater. Mar Chem 29(1):19-31

Ringuet S, Mackenzie FT (2005) Controls on nutrient and phytoplankton dynamics during normal flow and storm runoff conditions, southern Kaneohe Bay, Hawaii. Estuaries 28(3):327-337

Ruttenberg KC, Canfield DE (1994) Chemical distribution of phosphorus in suspended particulate matter from twelve North American rivers: evidence for bioavaialability of particulate-P. EOS 75(3):110

Schlesinger WH (1997) Biogeochemistry: an analysis of global change. Academic Press, San Diego

Schroeder T (1993) Climate controls. In: Sanderson M (ed) Prevailing trade winds. University of Hawaii Press, Honolulu

Smith SV, Kimmerer WJ, Laws EA et al (1981) Kaneohe Bay sewage experiment: perspectives on ecosystem responses to nutritional perturbation. Pac Sci 35(4):279-395

Stamski RE (2003) Trapping of land-derived sediment by macroalgae on the South Molokai reef flat, Hawaii. GSA Annual Meeting, Seattle, Geological Society of America

Sundby B, Gobeil C, Silverberg N et al (1992) The phosphorus cycle in coastal marine sediments. Limnol Oceanogr 37(6):1129-1145 
Syvistski JPM, Milliman JD (2007) Geology, geography, and humans battle for dominance over the delivery of fluvial sediment to the coastal ocean. J Geol 115:1-19

Syvistski JPM, Vörösmarty C, Kettner AJ, Green P (2005) Impact of humans on the flux of terrestrial sediment to the global coastal ocean. Science 308:376-380

Tenorio PA, Young RHF, Whitehead HC (1969) Identification of return irrigation water in the subsurface: water quality. Water Resources Research Center, Honolulu

Visher FN, Mink JF (1964) Ground-water resources in southern Oahu, Hawaii. U.S. Geological Survey, Honolulu

Wong MF (2001) Sedimentation history of Waimaluhia reservoir during highway construction, Oahu, Hawaii, 1983-98. U.S. Geological Survey, Honolulu, p 20

Wu I-P (1969) Hydrograph study and peak discharge determination of Hawaiian small watersheds: Island of Oahu. Water Resources Research Center, Honolulu, p 85

Tennessee Valley Authority (various years). Summary data, National Fertilizer and Environmental Research Center 